\title{
The Effects of Output Task Types on Noticing and Learning of English Past Modals: A Case of Intermediate Persian Adult Learners of English
}

\author{
Afshin Ghari (Corresponding Author) \\ Iran Language Institute, Esfahan, Iran \\ Email: afshin123ghari@gmail.com \\ Ahmad Moinzadeh \\ Department of English, the University of Isfahan, Isfahan, Iran
}

\begin{abstract}
The noticing function of output has been investigated by a number of researchers in the field of Second Language Acquisition (SLA) (e.g. Izumi, S., 2002, Izumi, S., Bigelow, M., 2000, Izumi, S., Bigelow, M., Fujiwara, M., Fearnow, S., 1999, Song and Suh, 2008). Still, the nature of such noticing and its effect on subsequent learning of English grammar has not been thoroughly investigated. The present study investigated the effect of output and the relative efficacy of two different output task types (reconstruction task and picture-cued writing task) on the noticing and learning of English past modals. Ninety four subjects remained to participate in our experiment. The results of the study offered some evidence that output task types better promote both the noticing and learning of the target structure. The positive effect of output demonstrated in this study is consistent with the hypothesized function of output in SLA.
\end{abstract}

Index Terms - output, noticing, grammar teaching, task types, English past modals

\section{INTRODUCTION}

Whether grammar should be a primary focus of language instruction, should be eliminated entirely, or should be subordinated to meaning-focused use of the target language is still a matter of controversy among the scholars in SLA (Pica, 2000). Over the past few decades, there have been some arguments against grammar teaching and some in support of it. Current research in SLA has reconsidered the role of grammar in the L2 classroom and has re-evaluated the grammar as a necessary component of language instruction (Nassaji and Fotos, 2004).

Arguing against Krashen's Input Comprehensible Hypothesis, Swain (1985) proposed a hypothesis and termed Comprehensible Output Hypothesis, claiming that comprehensible output $(\mathrm{CO})$ is the output that extends the linguistic repertoire of the learner as he or she attempts to create precisely and appropriately the meaning desired (p. 252). Besides, she argued that the role of learner production of $\mathrm{CO}$ is independent in many ways of the role of comprehensible input, claiming that $\mathrm{CO}$ is also an essential mechanism which helps SLA in many ways. In proposing the Output Hypothesis, Swain (1985) argued that producing the target language (TL) may serve as "the trigger that forces the learner to pay attention to the means of expression needed in order to successfully convey his or her own intended meaning" (p.249).

Of the four functions of output specified in the current version of the Output Hypothesis (Swain, 1993, 1995, 1998), one is the noticing function. The noticing function of output posits that learners may notice the gap in their interlanguage (IL) knowledge in an attempt to produce the TL, which then prompts them to solve their linguistic deficiency in ways that are appropriate in a given context (Izumi, 2002, p.545).

In the same line, the present study is founded on the basis that L2 learners need to attend to the language input for acquisition. Hence, this research will be an attempt to investigate whether different output ask types can function as an important trigger that directs learners' attention to the linguistic items while processing for meaning.

We replicated the study done by Song and Suh (2008). This study was done in Korea and with a small number of participants (fifty two). The linguistic structure under analysis in that study was the past counterfactual conditional. In this study, we investigated English past modals with a higher number of participants (ninety four). In fact, the researchers were motivated to carry out the replication of this study in order to find out the effects of the two output task types (picture-cued writing task and reconstruction task) Son and Suh (2008) made use of in their study on the noticing and learning of English past modals in another EFL context (Iran) with another group of participants and in two dimensions of learning (recognition and production). We did this research to see whether different contexts have any effects on the findings of the study, hoping to come up with new findings.

\section{REVIEW OF LITERATURE}

\section{A. Attention and Noticing}


Considering the assumption that attention plays a crucial role in language learning, much of SLA research has focused on investigating the types of tasks that promote learners' attention to a specific linguistic target. Recent research in cognitive psychology and SLA has also investigated the role of attention in mediating input and learning. Findings of such studies indicate that attention is necessary for learning to take place (see Robinson, 1995; Schmidt, 1990, 1995, 2001; and Tomlin \& Villa, 1994). Schmidt (2001) has simply stated that "people learn about the things that they attend to and do not learn much about the things they do not attend to".

Most of the studies on input enhancement (Rutherford and Sharwood Smith, 1985; Sharwood Smith, 1993), focus on form (Doughty, 2001; Doughty and Williams, 1998; Long, 1991; Long and Robinson, 1998), and the noticing function of output (Izumi, 2002; Izumi and Bigelow, 2000; Izumi et al., 1999) are based on the assumption that directing learners' attention to form during meaning-oriented learning activities helps them to acquire both form and meaning.

\section{B. Output and Noticing}

There seems to be a global consensus, over decades of research in SLA, that input plays a significant role in learners' acquisition of an L2. Current SLA research, however, goes beyond the provision of just comprehensible input (Krashen, 1985), which is taken to be a necessary but insufficient prerequisite for learning to take place (Ellis, 1994; LarsenFreeman \& Long, 1991; and Long, 1996, for reviews). Rather, it seeks to obtain a more precise understanding of how learners process, or interact with, input to develop their IL competence (Izumi, 2002).

Since the time Swain proposed the Output Hypothesis (1995, 1998, 2000, 2005), output has been considered not only as an end product of learning, but also as a significant factor to promote L2 learning (e.g., Izumi and Bigelow, 2000; Swain and Lapkin, 1995).

Swain (1993, 1995, and 1998) specified four functions of output: developing automacity in language use; hypothesistesting function; metalinguistic function; noticing/triggering function. Of the four mentioned functions, the focus of the present study is related to the noticing function. The noticing function of output states that while learners are producing the target language, they might "notice that they do not know how to say (or write) precisely the meaning they wish to convey" (Swain, 2005, p. 474), which that time might focus their attention on their linguistic deficiency and consequently, try to work out a solution.

To investigate this issue, Izumi and Bigelow (2000) and Izumi et al. (1999), in a two-stage study, focusing on the English past hypothetical conditional, compared an experimental group that was given output opportunities and subsequent exposure to relevant input and a control group that was exposed to the same input first and then asked to answer comprehension questions on the input. The output tasks were a reconstruction writing task and an essay-writing task. Noticing was done by underlining. The two studies were the same in every aspect except in the order of the two output tasks in the two phases. In Izumi et al. (1999), the reconstruction task was given in phase 1 and one week after phase 1, an essay-writing task was given in phase 2, whereas in Izumi and Bigelow (2000), the order of tasks was reversed to examine if task ordering plays any role in accounting for the results.

The effects of output in promoting noticing of the form were not substantiated in the two studies, perhaps because of the nature of the comprehension questions, individual variation, and type of target form (Izumi et al., 1999; Izumi and Bigelow, 2000). The studies revealed contrasting findings: Izumi et al. (1999) found the experimental group made a greater improvement on the production test (after the second phase treatment) than did the control group, while Izumi and Bigelow (2000) found no advantage for the experimental group on any of the post-tests. No clear-cut differences between the two groups were posited to be due to the impacts of the input flood and the true-false comprehension questions used for the control group (Izumi and Bigelow, 2000).

On the other hand, Izumi (2002) lent support to the attention-inducing function of output in a more controlled study. Building on the earlier studies, he aimed to investigate whether and how output (reconstruction task), visual input enhancement, together or separately, promote noticing and acquisition of English relativization. This study involved one control group and four treatment groups who differed in respect of output requirements and exposure to enhanced input. From the study, it was found that the participants engaged in the output treatments outperformed the subjects exposed to the same input for the purpose of comprehension only in learning the target form, although they did not outperform them in noticing the target form.

In the comparison of the two studies mentioned above, Izumi and Bigelow (2000) found that the experiment group learners' essays showed greater individual variation than did their text reconstructions. They argued that comparatively greater freedom given in the essay-writing task leads different learners to attend to varied aspects of the input subsequently provided, whereas the reconstruction task that targets the specific grammatical structure has an advantage in promoting noticing the gap. Instead of using an essay-writing task, whose task type seems to make it difficult for learners to attend to a specific form, the present study is going to employ another type of output task - a picture-cued writing task, which will be designed to provoke learners' attention to form as well as to give learners more flexibility than reconstruction, and compares the two tasks in their effect on noticing and learning of a targeted form.

In a recent study, Song and Suh (2008) also investigated the role of output and the relative efficacy of two different types of output tasks (reconstruction and pictured-cued writing task) in noticing and learning of the English past counterfactual conditional. They found that more acquisition occurred for those who had an opportunity to produce an output than those who did not, though none of the tasks they used resulted in a greater noticing and learning of the 
linguistic target. In fact, they found differences between those who had output opportunities and those who did not, but did not find any differences in the relative efficacy of the two output tasks.

Among these studies, a research issue which has received relatively less attention from researchers and has produced mixed results is whether output tasks better promote noticing and learning of a target linguistic form than non-output tasks. More specifically, research on the effects of output in comparison with comprehension task (Izumi, 2002) and the relative efficacy of different output tasks and input comprehension task has produced completely different results (Izumi and Bigelow, 2000; Izumi et al., 1999). Therefore, more research needs to be done to investigate what the suitable means of getting learners to focus on form are.

\section{RESEARCH QUESTIONS}

To shed more light on our insights of the impact of output on noticing and learning in SLA and of the possible efficacy of different task types on SLA, this study investigated the relative effectiveness of two different types of output tasks and a non-output task. The research questions were as follows:

Do Different output task types (a picture-cued writing task and a reconstruction task) better promote noticing of the targeted structure than a non-output task (a reading comprehension task)?

Do Different output task types better promote learning regarding the recognition of the targeted structure than a nonoutput task?

Do Different output task types better promote learning regarding the production of the targeted structure than a nonoutput task?

Based on the above questions the following null hypotheses were made:

$H_{0} 1$. Different output task types and a non- output task type are not different in promoting noticing of the targeted structure.

$H_{0}$ 2. Different output task types and a non-output task type are not different in promoting learning regarding recognition of the targeted structure.

$H_{0} 3$. Different output task types and a non-output task type are not different in promoting learning regarding production of the targeted structure.

\section{METHOD}

\section{A. Participants}

This study was conducted with 136 intermediate English language learners (aged 18-25) studying at an English language center in Esfahan. These 136 students happened to have already passed 6 courses in general English, which lent credence to their being at an intermediate level. All these 136 students participated in an Oxford Placement Test (OPT). 121 of them were chosen on the basis of their scores on the OPT to ensure that they were homogeneous regarding their knowledge of English grammar. Those who received extreme scores (one Standard Deviation above and below the mean) were excluded from our analyses. After a full week, the pretest was administered. Of these 121 participants 105 participated in the pretest. After a month, when all the treatments had been done, only 94 participants remained to take part in our posttest. Our final pool, however, consisted of 94 participants. 30 of them were in our control group, 34 of them were in our first experimental group (picture-cued writing) and finally 30 of them were in our second experimental group (reconstruction).

\section{B. Linguistic Structure under Analysis}

The target linguistic structures going under investigation were two types of past modals used for giving opinions or suggestions about actions in the past (i.e. should/ought to + have+ past participle of the main verb). The rationale for the selection of this type of structure was threefold:

First of all, students at the third grade of this English language center had not been exposed to this kind of linguistic item during their instruction until then. Hence, by selecting a structure with which participants were totally unfamiliar prior to the study, we could make sure that whatever happened after the investigation might have been the results of our treatment.

Secondly, this linguistic item constitutes one part of the curriculum developed for the English learners who want to receive a TOEFL or an ILETS degree. In other words, those who are making themselves prepared for such formal tests are expected to be able to distinguish between these two structures and some other similar modals and know how to use these structures communicatively.

Finally, these two structures were used for investigation because Iranian learners seem to have difficulty in distinguishing between these and some other similar structures like must thave + P.P. They are said to have problems both in understanding the meaning of the sentences in which such structures are used and communicating themselves using them.

\section{Instrumentation}

1. English Proficiency Test 
The grammar section of an OPT was utilized in order to gain a perception of the grammatical knowledge of the participants and in order to make sure that they are homogeneous regarding their knowledge of English grammar. This test consisted of 100 (multiple-choice) items to which our participants answered.

2. Pre and Post Test on Past Modals

There were two types of pre- and post-tests (see Appendix 1 for sample questions of these tests): (1) a recognition test, designed to assess the participants' receptive knowledge of the target structure, and (2) a written production task, designed to assess their use (i.e., produced output). Both were administered in a paper- and pencil format. Reasoning that the interval length (1 month) between the pre-test and the post-test was long enough that the learners could not remember the questions, the same form was utilized in administering both pre- and post-tests.

The recognition test consisted of 30 items, of which 23 used the target structures and 7 served as distractors. To avoid drawing the participants' attention to the target features during the pre and post-testing, which in turn would jeopardize the validity of the treatment, some distractors, all grammatical, were included in the test

Of these 23 items, 12 used the target form 'should have past participle', of which 8 were correct and 4 incorrect. Eleven out of 22 items used the target form 'ought to have past participle' of which 8 were correct and three incorrect. They were instructed to make a judgment whether or not each sentence was correct and, if incorrect, to underline the incorrect part and correct it.

The production test (see Appendix 2 for sample questions) included 2 sets of contexts, each of which was designed to elicit 4 sentence items calling for the target structure. Each context was explained in Farsi and a few words were given. A prompt (e.g., He should...or She ought to ....) under each item was written to ensure the participants produce the target forms.

\section{Procedure}

An overview of the experimental procedure for this study can be seen in Figure 1 below. The experimental sequence of the study was carried out over a period of approximately one month. First, an OPT was administered to all of the participants. Then, six intact classes were randomly assigned to three groups: picture-cued writing (EG 1); reconstruction (EG 2); non-output or comparison (CG). One week prior to the first treatment session all the participants took the pre-test which consisted of a recognition test and a written production test (see Appendix 2 for questions of the pre-test). Then, the three groups underwent different treatments. The experimental treatment consisted of three sessions. The second treatment session took place a full week after the first treatment session. The third treatment session also took place a full week after the second treatment session. The third treatment session was followed by a post-test a week later. In an attempt to control for outside exposure to the target form, after completing the post-test, the learners were asked whether they had consulted with anyone or anything about the target form. The data from those who reported having done so were all discarded. The data from those who were absent from any of the three treatment sessions or did not take the post-test were also discarded. Before excluding some participants to control for outside exposure to the target form, there were thirty five participants in each group. For these reasons, the size of each cell turned out to be different. There were 30 participants in the reconstruction task condition, 34 in the picture-cued writing task condition, and 30 in the non-output condition. 


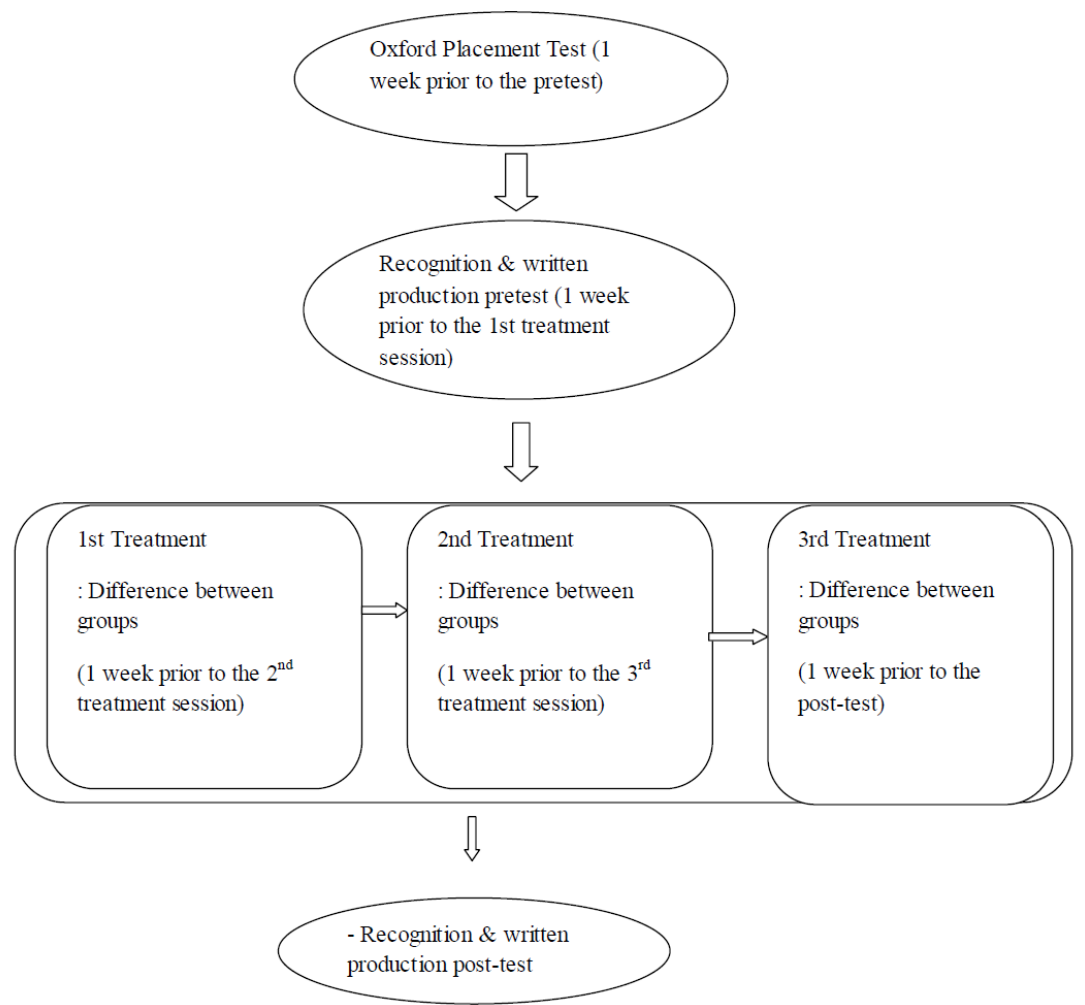

Figure 1: An Overview of the Experimental Procedure

\section{E. Treatment}

Figure 2 below shows an overview of the sequence of one treatment session for each group. The treatment conditions differed in terms of whether or not the participants were asked to produce output $(+/-\mathrm{O})$, and $+\mathrm{O}$ condition was further controlled with output task type: picture-cued writing (EG 1); reconstruction (EG 2). The other two treatment sessions were exactly the same as the first treatment except the content of reading texts. At the beginning of each treatment session, all group participants were informed of the task that they were going to do. They were asked to read the text with approximately $70 \%$ of sentences containing the past modals (should have past participle and ought to have past participle) and to underline the parts that they felt were necessary for the subsequent task. They were not allowed to look back at the text while completing their subsequent tasks. After reading the given text, the reconstruction group was asked to reconstruct the input passage they had just read as accurately as possible on a sheet of paper. A general picture relevant to the text they had just read with a few vocabulary prompts were provided in the output sheets considering there is a possibility that reconstruction may place a heavy cognitive burden on the learners (see Appendix 3). The picture cues were believed to lessen the memory load of remembering a story for EG 2. EG 1 participants were given picture and vocabulary prompts designed to elicit the targeted contexts, and completed a short guided writing based on them. The learners were encouraged to use the words written below each picture to write one sentence. Appendix 4 contains a sample picture prompt. Without looking back at the input text, the non-output group answered comprehension questions. The rationale of inclusion of the comprehension questions was to "prevent inadvertently drawing the learners' attention to form (Izumi et al., 1999, p. 448)". The participants in all three groups were shown the same text a second time. EG 1 and EG 2 received a second reconstruction opportunity and a second picture-cued writing opportunity respectively, and the CG answered the same questions regarding the content of the text. 


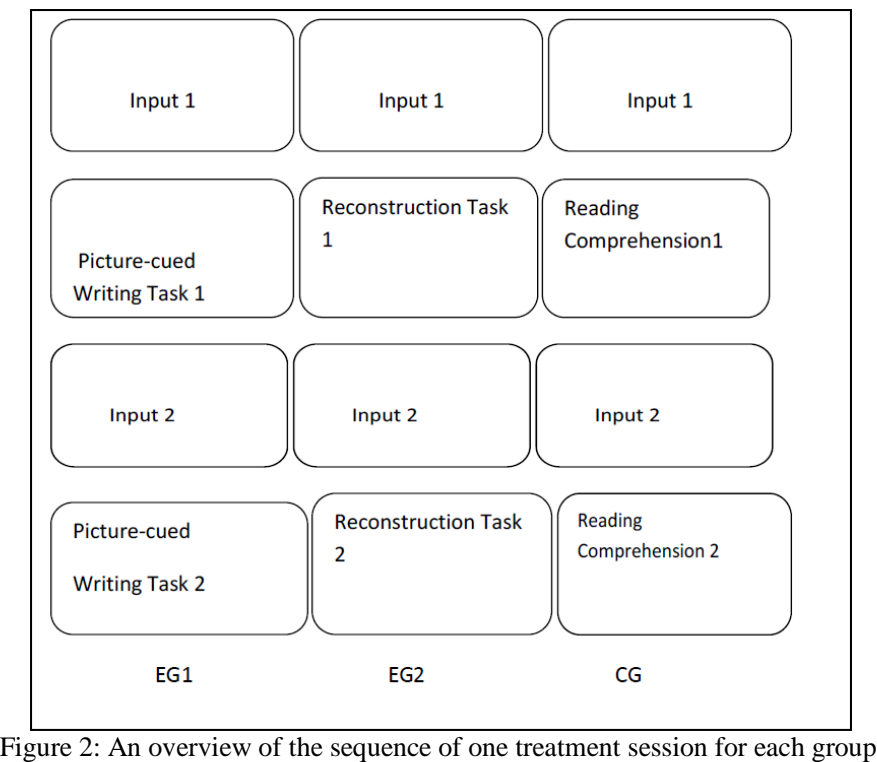

\section{CODING OF THE DATA}

\section{A. Underlining Scoring}

To examine noticing of the target form, underlines made on the first input of the first session and the second input of the third session were scored by counting total items underlined and then by obtaining a percentage of past modal (should have past participle and ought to have past participle) related underlined items. The following words or morphemes contained in past modal sentences were considered as past modal-related: modal verbs (should, ought to), the aspectual auxiliary (have), copula in the past participle ending (-ed and -en). The underlines were scored by one of the researchers and a second rater. Ten percent of the data were randomly selected and coded by both the researcher and a second rater. Inter-rater agreement was $92 \%$ for identification of past modal related items.

\section{B. Coding of Recognition Test Scores}

All the test items that were not answered were excluded from scoring. One point was given for each correct target response. A half point was given when the learners made a correct judgment whether each sentence was correct and underlined the incorrect part. Zero point was given when the learners made an incorrect judgment about each sentence. Test scores were calculated for each participant by dividing the total correct scores by the total number of the items answered. Finally, the score were converted in percentage for the sake of simplicity in doing statistical analyses.

\section{Coding of Written Production}

The production data obtained from pre- and post-tests were coded using a target-like use (TLU) analysis. It was carried out by dividing the number of target-like past modal sentences the learners produced by the total number of the target sentences attempted. The TLU analysis was utilized to examine target-like performance of each sentence. After a training session on $10 \%$ of the production data, the researcher and a second rater coded approximately $10 \%$ of the production data, achieving inter-rater agreement at $93 \%$.

\section{STATISTICAL ANALYSES AND RESULTS}

\section{A. The Language Proficiency Test}

In order to build up three rather homogenous groups as to the language proficiency level, the descriptive statistics, i.e., the means, standard deviations, and the standard error of the means of the proficiency test scores were calculated. It was proved that all three groups were similar regarding their English proficiency. Table 1 shows the descriptive statistics and Table 2 indicates the results of the ANOVA.

TABLE 1

DESCRIPTIVE STATISTICS OF THE PROFICIENCY TEST

\begin{tabular}{lllll}
\hline Groups & $\mathrm{N}$ & Mean & SD & SEM \\
\hline CG & 30 & 51.13 & 4.51 & .82 \\
EG1 & 34 & 50.73 & 4.33 & .74 \\
EG2 & 30 & 50.40 & 4.65 & .84 \\
\hline
\end{tabular}


TABLE 2

ANOVA RESULTS FOR THE PROFICIENCY TEST

\begin{tabular}{llllll}
\hline Source & SS & df & MS & F & Sig. \\
Between Groups & 8.088 & 2 & 4.044 & .200 & .819 \\
Within Groups & 1839.284 & 91 & 20.212 & & \\
Total & 1847.372 & 93 & & & \\
\hline
\end{tabular}

As can be seen in Table 2, the observed $\mathrm{F}$ is not significant because the level of significance is .81 which is higher than .05. Therefore, the three groups of the study are almost similar regarding their knowledge of English grammar and we can be sure that the three groups are homogeneous.

\section{B. Noticing}

The noticing issue has been investigated by first subtracting the noticing scores gained from the second input in the third session (last input) from the noticing scores gained from the first input in the first session (first input). In this way, the amount of change between the first input and the last input was calculated. As a result, three sets of scores were gained, one for each group (CG, EG1, and EG2). Table 3 reveals the descriptive statistics for these scores.

TABLE 3

DESCRIPTIVE STATISTICS FOR THE NOTICING SCORES

\begin{tabular}{lllll}
\hline Groups & $\mathrm{N}$ & Mean & SD & SEM \\
\hline CG & 30 & .65 & 2.65 & .48 \\
EG1 & 34 & 26.99 & 14.03 & 2.40 \\
EG2 & 30 & 17.30 & 10.29 & 1.87 \\
\hline
\end{tabular}

The above table shows that the three means are different. In order to find out whether or not the difference is significant, a one-way ANOVA was run. Table 4 presents the results of this ANOVA.

TABLE 4

ANOVA RESULTS FOR THE NOTICING SCORES

\begin{tabular}{llllll}
\hline Source & SS & Df & MS & F & Sig. \\
\hline Between Groups & 11207.433 & 2 & 5603.716 & 52.148 & .000 \\
Within Groups & 9778.654 & 91 & 107.458 & & \\
Total & 20986.087 & 93 & & & \\
\hline
\end{tabular}

As can be seen in Table 4 the amount of F-observed is significant $(\mathrm{F}=52.148, \mathrm{p}=.000)$. Then a Scheffe post hoc test was employed to determine the exact area(s) of the difference(s). Table 5 depicts the results of the post hoc test.

TABLE 5

POST-HOC SCHEFFE TEST FOR NOTICING

\begin{tabular}{llll}
\hline Group & Group & Mean Difference & Sig. \\
\hline CG & EG1 & $-26.34706^{*}$ & .000 \\
& EG2 & $-16.65333^{*}$ & .000 \\
\hline EG1 & CG & $26.34706^{*}$ & .000 \\
& EG2 & $9.69373^{*}$ & .002 \\
\hline \multirow{2}{*}{ EG2 } & CG & $16.65333^{*}$ & .000 \\
& EG1 & $-9.69373^{*}$ & .002 \\
\hline & *The mean difference is significant at the .05 level
\end{tabular}

As can be seen in Table 5, both experimental group 1 (picture-cued writing task) and experimental group 2 (reconstruction task) outperformed the control group. However, EG1 had better results in comparison with EG2. This means that output task types performed better than a non-out task type in promoting the noticing of the targeted structure. Furthermore, picture-cued writing task also outperformed the reconstruction task in promoting noticing of the targeted structure. Therefore, the first null hypothesis stating, "output task types are not different in promoting noticing of the targeted structure" can safely be rejected.

\section{Learning}

In this study, the learning issue was considered in two different dimensions, namely, the recognition of the linguistic target, and the production of the target from. The recognition and production scores gained from the pretest and the posttest were compared. The descriptive statistics of the scores from the pre and posttests are shown below in Table 6 . 
TABLE 6

DESCRIPTIVE STATISTICS FOR THE PRE AND POSTTESTS

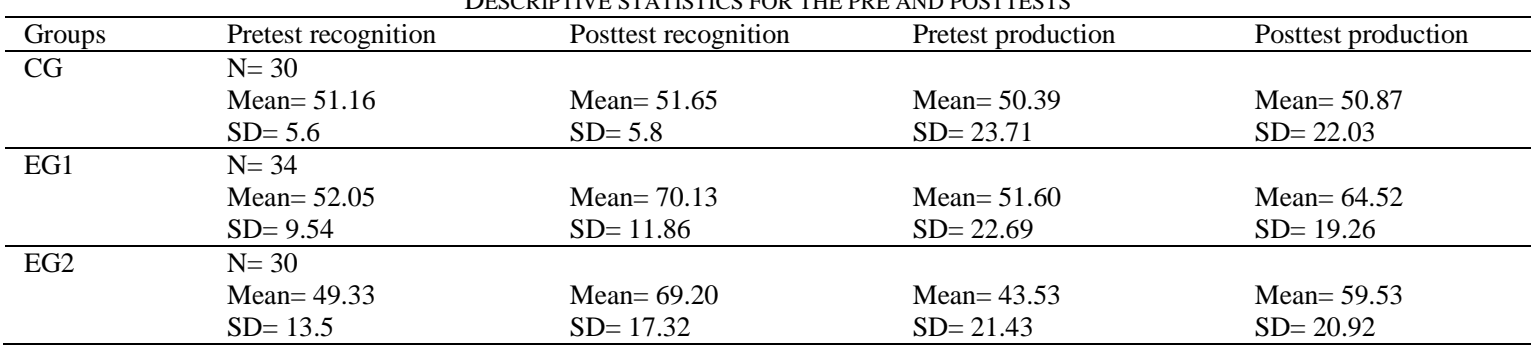

In fact, the production scores of the posttest were subtracted from the production scores of the pretest, and the same thing was done for the recognition scores of the pretest and posttest. Then a score for each individual in each group was obtained which was the result of this computation.

1. Learning regarding Recognition

To determine the effects of different output task types and a non-output task type on learning regarding the recognition of the targeted structure, the sets of scores which were obtained with regard to recognition were compared through applying a one-way ANOVA. Table 7 indicates the descriptive statistics for these sets and Table 8 shows the results of the ANOVA.

TABLE 7

DESCRIPTIVE STATISTICS FOR THE LEARNING REGARDING RECOGNITION SCORES

\begin{tabular}{lllll}
\hline Groups & $\mathrm{N}$ & Mean & SD & SEM \\
\hline CG & 30 & .48 & 1.74 & .31 \\
EG1 & 34 & 18.08 & 13.34 & 2.28 \\
EG2 & 30 & 19.87 & 13.74 & 2.50 \\
\hline
\end{tabular}

TABLE 8

ANOVA RESULTS FOR LEARNING REGARDING RECOGNITION

\begin{tabular}{llllll}
\hline Source & SS & df & MS & F & Sig. \\
\hline Between Groups & 6994.534 & 2 & 3497.267 & 27.819 & .000 \\
Within Groups & 11440.165 & 91 & 125.716 & & \\
Total & 18434.699 & 93 & & & \\
\hline
\end{tabular}

As can be seen in Table 8, the amount of F-observed is significant ( $F-27.819, p=.000)$. In other words, the three groups performed differently on the recognition test. In order to find out which groups were different in this regard, a Scheffe post hoc test was run. Table 9 reveals the results of this Scheffe test.

TABLE 9

THE RESUlTS OF THE SCHEFFE POST-HOC TEST FOR LEARNING REGARDING RECOGNITION

\begin{tabular}{llll}
\hline Group & Group & Mean Difference & Sig. \\
\hline CG & EG1 & $-17.59931^{*}$ & .000 \\
& EG2 & $-19.38767^{*}$ & .000 \\
\hline EG1 & CG & $17.59931^{*}$ & .000 \\
& EG2 & -1.78835 & .817 \\
\hline EG2 & CG & $19.38767^{*}$ & .000 \\
& EG1 & 1.78835 & .817 \\
\hline \multicolumn{5}{c}{$*$ The mean difference is significant at the .05 level. }
\end{tabular}

As Table 8 shows, the two experimental groups outperformed the control group in promoting learning regarding recognition. However, EG1 and EG2 were not statistically different. That is, although both of the output task types (picture-cued writing task and reconstruction task) had an effect on promoting learning regarding recognition, they did not differ in their effects on learning regarding recognition. Therefore, the second null hypothesis stating "different output task types and a non-output task type are not different in promoting learning regarding the recognition of the targeted structure" can safely be rejected.

2. Learning regarding Production

To determine the effects of different output task types and a non-output task type on learning regarding the production of the targeted structure, the sets of scores which were obtained with regard to production were compared through applying another one-way ANOVA. Table 10 reveals the descriptive statistics for these sets and Table 11 indicates the results of the ANOVA. 
TABLE 10

DESCRIPTIVE STATISTICS FOR THE LEARNING REGARDING PRODUCTION SCORES

\begin{tabular}{lllll}
\hline Groups & $\mathrm{N}$ & Mean & SD & SEM \\
\hline CG & 30 & .48 & 13.38 & 2.44 \\
EG1 & 34 & 12.09 & 13.54 & 2.32 \\
EG2 & 30 & 16.00 & 13.13 & 2.39 \\
\hline
\end{tabular}

TABLE 11

\begin{tabular}{llllll}
\multicolumn{7}{c}{ TABLE 11} \\
ANOVA RESUlTS FOR THE LEARNING REGARDING PRODUCTION SCORES \\
\hline Source & SS & df & MS & F & Sig. \\
Between Groups & 4090.753 & 2 & 2045.376 & 11.452 & .000 \\
Within Groups & 16253.568 & 91 & 178.611 & & \\
Total & 20344.321 & 93 & & & \\
\hline
\end{tabular}

As can be seen in Table 11, the amount of F-observed is significantly high enough to claim that the three groups under investigation acted differently on the test of production $(\mathrm{F}=11.452, \mathrm{p}=.000)$. Once again, to find the exact place(s) of difference(s), a second Scheffe post hoc test was employed. Table 12 presents the results of this post hoc test.

As Table 12 shows, the two experimental groups outperformed the control group in promoting learning regarding production. However, in this test again the difference between EG1 1 and EG 2 was not statistically significant. That is, although both of the output task types (picture-cued writing task and reconstruction task) had an effect on promoting learning regarding production, they did not differ in their effects on learning regarding production. As a result, it is safe to reject the third null hypothesis stating "different output task types a non-output task type are not different in promoting learning regarding production of the targeted structure".

TABLE 12

\begin{tabular}{llll}
\multicolumn{2}{c}{ PoST-HOC RESULTS FOR LEARNING REGARDING PRODUCTION SCORES } \\
\hline Group & Group & Mean Difference & Sig. \\
\hline CG & EG1 & $-12.44329^{*}$ & .002 \\
& EG2 & $-15.52467^{*}$ & .000 \\
\hline EG1 & CG & $12.44329^{*}$ & .002 \\
& EG2 & -3.08137 & .656 \\
\hline EG2 & CG & $15.52467^{*}$ & .000 \\
& EG1 & 3.08137 & .656 \\
\hline
\end{tabular}

\section{DISCUSSION}

The first research question addressed the effect of different output task types and a non-output task type on noticing of the targeted structure. In response to this question, the data confirmed that different output task types, whether picture-cued writing task or reconstruction task better promote noticing of the target structure than a non-out put task type. In addition, our results indicated that the picture-cued writing task also promoted noticing more than the reconstruction task (see Table 5). Thus, it can be claimed that the noticing function of output has been supported in this study.

Comparing these two output task types, the learners who were given the picture-cued writing task type noticed the structure better than the learners who were given the reconstruction task type. This might be due to the amount of attention participant paid to this task. In the reconstruction task, participants had to reconstruct the text and during this reconstruction they might have been distracted by some other structures in the input provided for them. By contrast, those participants who were engaged in doing the picture-cued writing task might have focused their attention on the targeted structure. Nearly all the details of the texts were shown in the pictures so the chance of getting distracted by other structures seemed to be less than the chance of getting distracted by the reconstruction task.

The second question focused on the effects of different output task types and a non-output task types on learning regarding recognition of the target structure. In response to this question, our data confirmed that those participants who produced output $(+\mathrm{O})$ outperform those who do not $(-\mathrm{O})$ in learning regarding recognition of the target structure (see Tables 7 and 8). Therefore, it can be claimed that Schmidt's Noticing Hypothesis is partly supported. According to this hypothesis better noticing leads to better learning. Both of our experimental groups who produced output better noticed the targeted structure than the control group and subsequently learned it.

However, our two experimental conditions did not yield different results. That is, although both of the output task types (picture-cued writing task and reconstruction task) had an effect on promoting learning regarding recognition, they did not differ in their effects on learning regarding recognition. This finding seems to be against Schmidt's Noticing Hypothesis. Although EG1 better noticed the targeted structure than EG2 and should have learned the structure better, it seems that the amount of noticing has been high enough for EG2 to learn it as well as EG1. 
Finally, the third research question aiming to address the effects of output task types and a non-output task type on learning regarding production of the target structure found positive results. In response to this question our data confirmed that output task types better promote learning regarding production of the target structure (see Tables 10 and 11). As Table 12 shows, our two experimental groups, those learners who had an output opportunity, outperformed the control group, those learners who did not produce output, in promoting learning regarding production. However, in this test again the difference between EG 1 and EG 2 was not statistically significant. That is, although both of the output task types (picture-cued writing task and reconstruction task) had an effect on promoting learning regarding production, they did not differ in their effects on learning regarding production. This finding can also be accounted for by the tenable explanation given above for learning regarding recognition.

The positive effect of output demonstrated in this study is consistent with the hypothesized function of output in SLA. Based on previous research (Izumi et al. (1999), Izumi and Bigelow (2000), Izumi (2002), Song and Suh (2008)), that indicates insufficiency of comprehensible input in driving L2 development and on research that points to the importance of attention in learning, it was hypothesized that learners' attention somehow needs to be drawn to the critical features of input to promote their learning. Output was considered to be one means to achieve this goal by prompting the learners to find problems in their IL by attempting to produce the target structure. Furthermore, it was assumed that, on exposure to relevant input immediately after their production experience, the heightened sense of problematicity would lead them to pay closer attention to what was identified to be a problematic area in their IL. In short, pushed output can induce the learners to process the input effectively for their greater IL development.

In terms of the total amount of noticing, it was revealed that our study and Song and Suh's (2008) had the same results. In other words, in both of the studies, output opportunities promoted significantly greater noticing of the target form than did the non-output condition. Furthermore, the picture-cued writing task was more effective in drawing learners' attention to the target form than the reconstruction task.

The result that all three groups were different in the noticing gain is not consistent with the general trends observed in the previous studies (e.g., Izumi and Bigelow, 2000; Izumi et al., 1999) where the output conditions did not result in greater noticing of the counterfactual conditional than did the non-output condition. In this vein, this outcome coincides with the hypothesized effects of 'pushed' output (Swain, 1995) in triggering noticing.

\section{LIMITATIONS AND FUTURE RESEARCH}

Acknowledging some limitations throughout the accomplishment of different phases, several suggestions can be made for future research. Most of all, this study failed to control time-on-task. The time-on-task needed for picture-cued writing, reconstruction, and reading comprehension might to have been equal in this study. Other studies are recommended to control this factor since the result of the study cannot be accounted for because of the difference between output and nonoutput but due to the fact that more time leads to better learning.

Next, future studies are expected to gather the data from a greater number of participants in an experimental design, rather than in a quasi-experimental design, to enhance external validity or generalizability.

Finally, the current study was done as an experiment with EFL learner participants at intermediate level. Students at other levels, elementary and advanced, were not studied in the present study. It is recommended that other studies be done with higher levels, too.

\section{APPLICATION AND IMPLiCATIONS OF THE FINDINGS}

The findings of this study are expected to have implications for the design of output tasks in educational settings and provide teachers and methodologists with new insights into designing varied task types in EFL classrooms. The results of this study are expected to indicate that output practice is more effective on noticing of a target form when learners are presented with opportunities to engage in the syntactic processing without posing a high cognitive burden to attend to the content words or other functional words.

\section{APPENDIX 1: RECOGNITION TEST (SAMPLE QUESTIONS FROM THE PRE-/POST-TEST)}

This coffee tastes awful. I'll complain to the waiter about it. Yes/No

John failed the test. He should have studied harder. Yes/No

He should asked me before he took my bike. Yes/No

We ought to taken a taxi when it rained. Yes/No

The cashier gave me too much money. I should have said something. Yes/No

APPENDiX 2: CONTEXTUALIZEd PRODUCTION TEST (SAMPLE QUESTIONS FROM THE PRE-/POST-TEST)

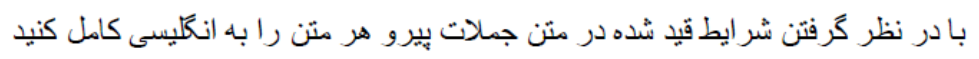

Ali's old car broke down on the highway late one night. He left the car on the side of the road and walked home. يك شب ديروقت ماشين قديمى على توى يه اتوبان خر اب شد. او ماثشينو كنارجاده كذاشت ويياده رفت خونه.

1. He should .................................................... (stop a stranger's car to ask for a ride) 
مبايستى دست ميكرفت برا يه ماشثين تا برستوندش

2. He ought to.

(walk to the nearest pay phone and call a tow truck).

$$
\text { مبايستى بياده تانزديك ترين باجه تلفن ميرفت وبر ايه جرثقيل زنح ميزد. }
$$

\section{APPENDIX 3: PICTURE CUES FOR THE RECONSTRUCTION (AN EXAMPLE FROM THE FORM USED IN THE 1ST TREATMENT} SESSION)

He was in a hurry and had an accident. He regrets the following things. Write as many sentences as you can.

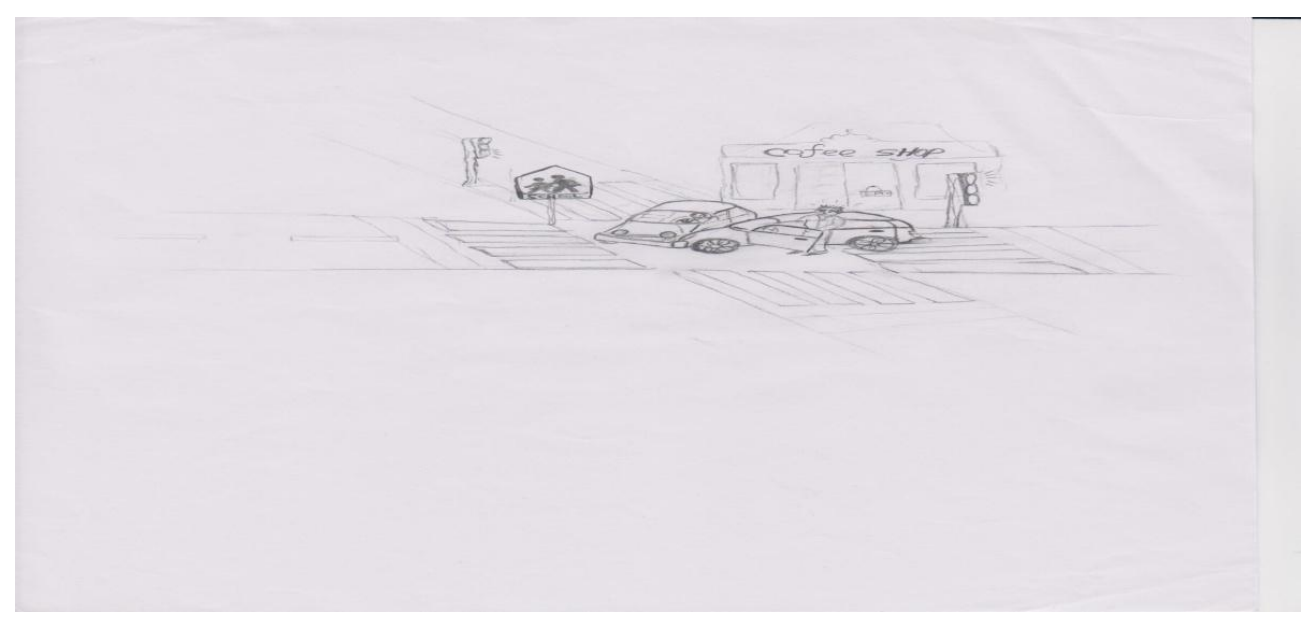

\section{APPENDIX 4: PICTURE PROMPT FOR THE PICTURE-CUED WRITING (EXAMPLES FROM THE FORM USED IN THE 1ST TREATMENT)}

He was in a hurry and had an accident. Now, he regrets the following things. Write a sentence under each picture using the words.

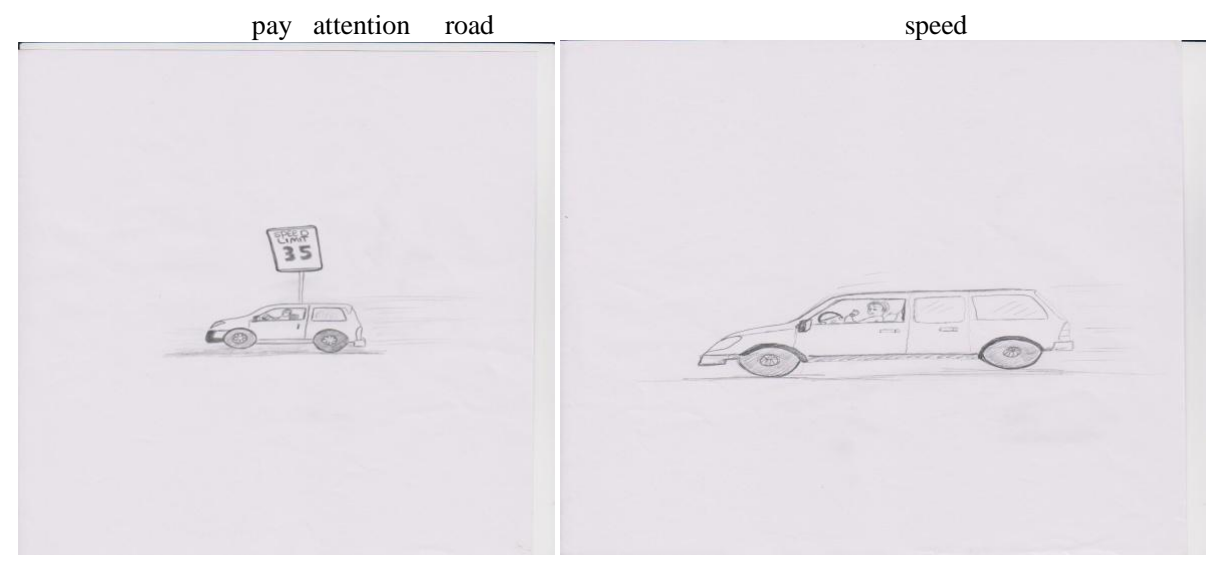

\section{APPENDIX 5: INPUT PASSAGE FOR THE NON-OUTPUT GROUP (AN EXAMPLE FROM THE FORM USED IN THE 1ST TREATMENT)}

Many years have passed since that dreadful day, the day my life changed forever, and looking back at things, I shouldn't have been speeding. I was late for work and all I could think about was getting there on time. I shouldn't have run the red light. The next thing I remember was the sound of the windshield shattering and people gathering all around me. I ought to have paid more attention to the school crossing sign. I should have paid more attention to the road. I was thinking about my work when I should have paid more attention to my driving. I ought to have followed the traffic rules. Now it's too late.

\section{REFERENCES}

[1] Doughty, C., Williams, J. (Eds.). (1998). Focus on Form in Classroom Second Language Acquisition. Cambridge, NY: Cambridge University Press. 
[2] Doughty, C.J. (2001). Cognitive underpinnings of focus on form. In: Robinson, P. (Ed.), Cognition and L2 Instruction. Cambridge University Press, Cambridge, UK, pp. 206-257.

[3] Ellis, R. (1994). The study of second language acquisition. Oxford: Oxford University Press.

[4] Izumi, S. (2002). Output, input enhancement, and the noticing hypothesis: An experimental study on ESL relativization. Studies in Second Language Acquisition 24, 541-577.

[5] Izumi, S., Bigelow, M., Fujiwara, M. \& Fearnow, S. (1999). Testing the output hypothesis: Effects of output on noticing and second language acquisition. Studies in Second Language Acquisition 21, 421-452.

[6] Izumi, S., Bigelow, M. (2000). Does output promote noticing and second language acquisition? TESOL Quarterly 34, $239-278$.

[7] Krashen, S. (1985). The Input Hypothesis. Longman, London.

[8] Larsen-Freeman, D., \& Long, M. (1991). An introduction to second language acquisition research. London: Longman.

[9] Long, M. (1991). Focus on form: a design feature in language teaching methodology. In: De Bot, K., Grinsberg, R., Kramsch, C. (Eds.), Foreign Language Research in Cross-cultural Perspective. John Benjamins, Amsterdam, pp. 39-52.

[10] Long, M. (1996). The role of the linguistic environment in second language acquisition. In W. C. Ritchie \& T. K. Bhatia (Eds.), Handbook of second language acquisition (pp. 413-468). San Diego, CA: Academic Press.

[11] Long, M., Robinson, P. (1998). Focus on form: Theory, research, and practice. In: Doughty, C., Williams, J. (Eds.), Focus on Form in Classroom Second Language Acquisition. Cambridge University Press, NY, pp. 15-41.

[12] Nassaji, H., Fotos, S. (2004). Current Developments in the Teaching of Grammar. Annual Review of Applied Linguistics 24, 126-145.

[13] Pica, T. (2000). Tradition and transition in English language teaching methodology. System 28, 1-18.

[14] Robinson, P. (1995). Attention, memory, and the "Noticing" hypothesis. Language Learning 45, 283-331.

[15] Rutherford, W., Sharwood Smith, M. (1985). Consciousness-raising and universal grammar. Applied Linguistics 6, $274-282$.

[16] Schmidt, R. W. (1990). The role of consciousness in second language learning. Applied Linguistics, 11(2), 129-158.

[17] Schmidt, R., (1995). Consciousness and foreign language learning: A tutorial on the role of attention and awareness in learning. In: R. Schmidt (Ed.), Attention and awareness in foreign language learning (pp. 1-63). Second Language Teaching and Curriculum Center, Hawai'i.

[18] Schmidt, R. W. (2001). Attention. In P. Robinson (Ed.), Cognition and second language instruction (pp. 3-32). Cambridge: Cambridge University Press.

[19] Sharwood Smith, M. (1993). Input enhancement in instructed SLA: theoretical bases. Studies in Second Language Acquisition $15,165-179$.

[20] Song, M. J., Suh, B. R. (2008). The effects of output task types on noticing and learning of the English past counterfactual conditional. System 36, 295-312.

[21] Swain, M. (1985). Communicative competence: some roles of comprehensible input and comprehensible output in its development. In: Gass, S., Madden, C. (Eds.), Input in Second Language Acquisition. Newbury House, Rowley, MA, pp. 235253.

[22] Swain, M. (1993). The output hypothesis: Just speaking and writing aren't enough. The Canadian Modern Language Review, 50, 158-164.

[23] Swain, M. (1995). Three functions of output in second language learning. In: Cook, G., Seildhofer, B. (Eds.), Principles and Practice in Applied Linguistics: Studies in Honour of H.G. Widdowson. Oxford University Press, Oxford, pp. 125-144.

[24] Swain, M. (1998). Focus on form through conscious reflection. In C. Doughty and J. Williams (eds): Focus on Form in Classroom Second Language Acquisition. Cambridge: Cambridge University Press.

[25] Swain, M., (2000). The output hypothesis and beyond: mediating acquisition through collaborative dialogue. In Lantolf, J.P. (Ed.). Sociocultural Theory and Second Language Learning. Oxford University Press, Oxford, pp. 97-114.

[26] Swain, M. (2005). The output hypothesis: theory and research. In Hinkel, E. (Ed.), Handbook on Research in Second Language Teaching and Learning. Lawrence Erlbaum, Mahwah, NJ, pp. 471-484.

[27] Swain, M., Lapkin, S. (1995). Problems in output and the cognitive processes they generate: A step towards second language learning. Applied Linguistics 16, 371-391.

[28] Tomlin, R. S., Villa, V. (1994). Attention in cognitive science and second language acquisition. Studies in Second Language Acquisition, 16, 183-202.

Afshin Ghari is an English teacher at Iran Language Institute in Esfahan, Iran. He has an M.A. in English Teaching from the University of Isfahan. He is interested in doing research on the effect of output tasks on learning a foreign language.

Ahmad Moinzadeh has a PhD in linguistics. He is an assistant professor of linguistics at the Department of English at the University of Isfahan, Isfahan, Iran. 